\title{
Synthesis of Thermally Spherical CuO Nanoparticles
}

\author{
Nittaya Tamaekong, ${ }^{1}$ Chaikarn Liewhiran, ${ }^{2}$ and Sukon Phanichphant ${ }^{3}$ \\ ${ }^{1}$ Program in Materials Science, Faculty of Science, Maejo University, Chiang Mai 50290, Thailand \\ ${ }^{2}$ Department of Physics and Materials Science, Faculty of Science, Chiang Mai University, Chiang Mai 50200, Thailand \\ ${ }^{3}$ Materials Science Research Center, Faculty of Science, Chiang Mai University, Chiang Mai 50200, Thailand
}

Correspondence should be addressed to Nittaya Tamaekong; tamaekong.nittaya@gmail.com

Received 6 September 2013; Accepted 29 November 2013; Published 8 January 2014

Academic Editor: Enrico Bergamaschi

Copyright (C) 2014 Nittaya Tamaekong et al. This is an open access article distributed under the Creative Commons Attribution License, which permits unrestricted use, distribution, and reproduction in any medium, provided the original work is properly cited.

Copper oxide $(\mathrm{CuO})$ nanoparticles were successfully synthesized by a thermal method. The $\mathrm{CuO}$ nanoparticles were further characterized by thermogravimetric analysis (TGA), differential thermal analysis (DTA), X-ray diffraction (XRD), scanning electron microscopy (SEM), energy dispersive X-ray spectrometry (EDS), and high resolution transmission electron microscopy (HRTEM), respectively. The specific surface area $\left(\mathrm{SSA}_{\mathrm{BET}}\right)$ of $\mathrm{CuO}$ nanoparticles was determined by nitrogen adsorption. The $\mathrm{SSA}_{\mathrm{BET}}$ was found to be $99.67 \mathrm{~m}^{2} / \mathrm{g}\left(d_{\mathrm{BET}}\right.$ of $\left.9.5 \mathrm{~nm}\right)$. The average diameter of the spherical CuO nanoparticles was approximately 6-9 $\mathrm{nm}$.

\section{Introduction}

Metal oxides play a very important role in many areas of chemistry, physics, and materials science [1-6]. The metal elements can form a large diversity of oxide compounds [7]. These elements can adopt much structural geometry with an electronic structure that can exhibit metallic, semiconductor, or insulator character. In technological applications, oxides are used in the fabrication of microelectronic circuits, sensors, piezoelectric devices, fuel cells, and coatings for the passivation of surfaces against corrosion and as catalysts. For example, almost all catalysts used in industrial applications involve an oxide as active phase, promoter, or "support." In the chemical and petrochemical industries, products worth billions of dollars are generated every year through processes that use oxide and metal/oxide catalysts [8]. For the control of environmental pollution, catalysts or sorbents that contain oxides are employed to remove the $\mathrm{CO}, \mathrm{NO}_{x}$, and $\mathrm{SO}_{x}$ species formed during the combustion of fossil-derived fuels $[9,10]$. Furthermore, the most active areas of the semiconductor industry involve the use of oxides [11]. Thus, most of the chips used in computers contain an oxide component.

Oxide nanoparticles can exhibit unique physical and chemical properties due to their limited size and high density of corner or edge surface sites. Particle size is expected to influence three important groups of basic properties in any material. The first one comprises the structural characteristics, namely, the lattice symmetry and cell parameters [12]. Bulk oxides are usually robust and stable systems with welldefined crystallographic structures. However, the growing importance of surface-free energy and stress with decreasing particle size must be considered: changes in thermodynamic stability associated with size can induce modification of cell parameters and/or structural transformations [13], and in extreme cases the nanoparticle can disappear due to interactions with its surrounding environment and the high surfacefree energy [14]. Nanomaterials have become important owing to their small size and large surface area. They exhibit unique properties which are not seen in bulk materials [15].

$\mathrm{CuO}$ has been studied as a $p$-type semiconductor material with narrow band gap of $1.2 \mathrm{eV}$, because of the natural abundance of its starting material, low-cost production processing, nontoxic nature, and reasonably good electrical and optical properties. $\mathrm{CuO}$ nanoparticles were of great interest due to their potential applications in a wide variety of areas including electronic and optoelectronic devices, such as microelectromechanical systems, field effect transistors, electrochemical cells, gas sensors, magnetic storage media, solar cells, field emitters, and nanodevices for catalysis. It has also been recently emphasized that, apart from the size, 
the shape of the nanostructure is equally important for controlling different properties [16].

However copper is an essential trace element for the normal function of many tissues, including the nervous system, immune system, heart, and skin, and for the formation of capillaries $[17,18]$, and copper is well metabolized by humans [19]. Copper(II) oxide has extremely low bioavailability (practically zero) and should not be taken in conditions of copper deficiency, especially as part of a multivitamin which also includes zinc or molybdenum [19]. Excessive zinc or molybdenum intake eliminates copper from the body. Copper oxide is used in vitamin supplements as a safe source of copper and over-the-counter treatments. Copper oxide is also used in consumer products such as pillowcases and socks, due to its cosmetic and antimicrobial properties [2023]. The risk of dermal sensitivity to copper is considered extremely minimal [24].

In this study, $\mathrm{CuO}$ was synthesized using ethanediolthermal method. Because of its low cost $\mathrm{CuO}$ is applied as gas sensing material to detect combustible, toxic, and pollution gases. Usually gas sensing properties of oxide semiconductors strongly depend on the surface of these materials. Thus, this research has been concentrating on improving high specific surface area of $\mathrm{CuO}$ nanoparticles.

\section{Methods and Procedures}

2.1. Synthesis of Nanoparticles. $\mathrm{CuO}$ nanoparticles were synthesized by the thermal method method. Copper (II) acetate $\left(\mathrm{Cu}\left(\mathrm{CH}_{3} \mathrm{COO}\right)_{2} \cdot x \mathrm{H}_{2} \mathrm{O}\right.$, Aldrich, 98\%) and sodium hydroxide $(\mathrm{NaOH}$, Merck, 99\%) were used as the precursors, and ethanediol $\left(\mathrm{C}_{2} \mathrm{H}_{6} \mathrm{O}_{2}\right.$, Ajex Finechem, 99.5\%) was used as the solvent. In a typical procedure to synthesize the $\mathrm{CuO}$ nanoparticles, $25 \mathrm{mM}$ of $\mathrm{Cu}\left(\mathrm{CH}_{3} \mathrm{COO}\right)_{2} \cdot x \mathrm{H}_{2} \mathrm{O}$ and $100 \mathrm{mM}$ of $\mathrm{NaOH}$ were dissolved in ethanediol at $80^{\circ} \mathrm{C}$ by stirring for $2 \mathrm{~h}$ on the basis of the following reaction:

$$
\begin{gathered}
\mathrm{Cu}\left(\mathrm{CH}_{3} \mathrm{COO}\right)_{2} \cdot x \mathrm{H}_{2} \mathrm{O}+\mathrm{C}_{2} \mathrm{H}_{6} \mathrm{O}_{2}+2 \mathrm{NaOH} \\
\longrightarrow \mathrm{Cu}(\mathrm{OH})_{2}+2 \mathrm{Na}\left(\mathrm{C}_{2} \mathrm{H}_{5} \mathrm{COO}\right)+x \mathrm{H}_{2} \mathrm{O} \\
\mathrm{Cu}(\mathrm{OH})_{2}+2 \mathrm{Na}\left(\mathrm{C}_{2} \mathrm{H}_{5} \mathrm{COO}\right)+x \mathrm{H}_{2} \mathrm{O} \\
\longrightarrow \mathrm{CuO}+2 \mathrm{Na}\left(\mathrm{C}_{2} \mathrm{H}_{5} \mathrm{COO}\right)+x \mathrm{H}_{2} \mathrm{O}
\end{gathered}
$$

The $\mathrm{pH}$ of the solution under continuous stirring was 9. Then, the final products were washed with DI water and ethanol several times by centrifugation. The obtained brown powder was subsequently dried at $80^{\circ} \mathrm{C}$ in air. The resultant powder was then characterized using TG/DTA for calcination temperatures.

2.2. Powder Characterizations. The thermogravimetric analysis (TGA) and differential thermal analysis (DTA) were carried on TGA7 and DTA7 (Perkin Elmer). The X-ray diffraction (XRD) patterns were correspondingly recorded with JEOL JDX-3530 operating with $\mathrm{Cu} \mathrm{K}_{\alpha}(\lambda=1.5405 \AA)$. The elemental compositions of nanoparticles were analyzed by EDS quantitative analysis (Oxford Instrument). The specific surface area $\left(\mathrm{SSA}_{\mathrm{BET}}\right)$ of the nanoparticles was measured by nitrogen adsorption at $77 \mathrm{~K}$ (Micromeritics Tristar) after degassing the sample for $1 \mathrm{~h}$ at $150^{\circ} \mathrm{C}$ under nitrogen fluctuation. The equivalent average primary particle diameter $d_{\mathrm{BET}}$ was calculated by $d_{\mathrm{BET}}=6 /\left(\rho_{\mathrm{CuO}} \times \mathrm{SSA} A_{\mathrm{BET}}\right)$ [25], where $\rho_{\mathrm{CuO}}$ is the density of $\mathrm{CuO}=6.5 \mathrm{~g} / \mathrm{cm}^{3}$ [26]. Finally, the accurate morphologies of nanoparticles were observed using HRTEM (JEOL JEM-2010).

\section{Results and Discussion}

The TGA/DTA profile for the $\mathrm{CuO}$ precursor was shown in Figure 1. The TGA curve showed a three-step decomposition of the precursor to form the $\mathrm{CuO}$. The weight losses were decomposed under excited temperatures ranging $35-166^{\circ} \mathrm{C}$, $166-287^{\circ} \mathrm{C}$, and $287-370^{\circ} \mathrm{C}$. The initial weight loss below $166^{\circ} \mathrm{C}(\sim 9 \%)$ was caused by the water evaporation (moisture) and organic solvent molecules according to two minor endotherms peaks on the DTA curves $\left(56-160^{\circ} \mathrm{C}\right)$ in this region. The second decomposition step of TGA curve at 166$287^{\circ} \mathrm{C}$ can be attributed to the pyrolysis and combustion of organic compounds form precursor and solvent which leave the system in the form of $\mathrm{CO}_{x}(x=1,2)$ and organic gases. This observation was consistent with the well-resolved exothermic in the DTA curves at approximately $163-300^{\circ} \mathrm{C}$ [27]. According to the temperature that was approximately up to $500^{\circ} \mathrm{C}$, here the $\mathrm{CuO}$ nanopowder was calcined at $500^{\circ} \mathrm{C}$ for $2 \mathrm{~h}$.

For XRD patterns of the $\mathrm{CuO}$ nanoparticles, all peaks can be confirmed to be the monoclinic phase of $\mathrm{CuO}$ (JCPDS no. 48-1548) as shown in Figure 2. The smaller size of $\mathrm{CuO}$ nanoparticles can be predicted consistently with the broadening diffraction peaks of XRD patterns. Moreover, the crystallite size based on the broadening diffraction peaks was approximately estimated from the corresponding X-ray spectral peak employing the Debye-Scherrer's formula (2) [28]. The calculated value was estimated to be $6.1 \mathrm{~nm}$ :

$$
d(\AA)=\frac{k \lambda}{\beta \cos \theta},
$$

where $k$ is an empirical constant equal to 0.9 as the spherical particles, $\lambda$ is the wavelength of the X-ray source (1.5405 $\AA$ ), $\beta$ is the full width at half maximum of the diffraction peak, and $\theta$ is the angular position of the diffraction peak. According to the BET method, the specific surface area $\left(\mathrm{SSA}_{\mathrm{BET}}\right)$ of $\mathrm{CuO}$ nanoparticles was measured to be $99.67 \mathrm{~m}^{2} / \mathrm{g}$. It was found that the calculated particle size of sample was $9.3 \mathrm{~nm} \mathrm{[25].}$ The accurate particle size and morphologies of $\mathrm{CuO}$ nanoparticle were confirmed by SEM and TEM bright-field images. Figures 3(a) and 3(b) showed the morphology of highly crystalline $\mathrm{CuO}$ nanoparticles from SEM/EDS and TEM analyses. The SEM micrograph clearly showed rough agglomeration of nanostructural homogeneities with spherical morphologies of $\mathrm{CuO}$ nanoparticles. The SEM observation showed the presence of agglomerated nanospheres with an average diameter of 10-20 nm. Therefore, from this observation only the rough morphology was found. Nevertheless, the accurate sizes and morphology of the nanoparticles can be estimated from the TEM analysis. While the SEM images provide $3 \mathrm{D}$ 


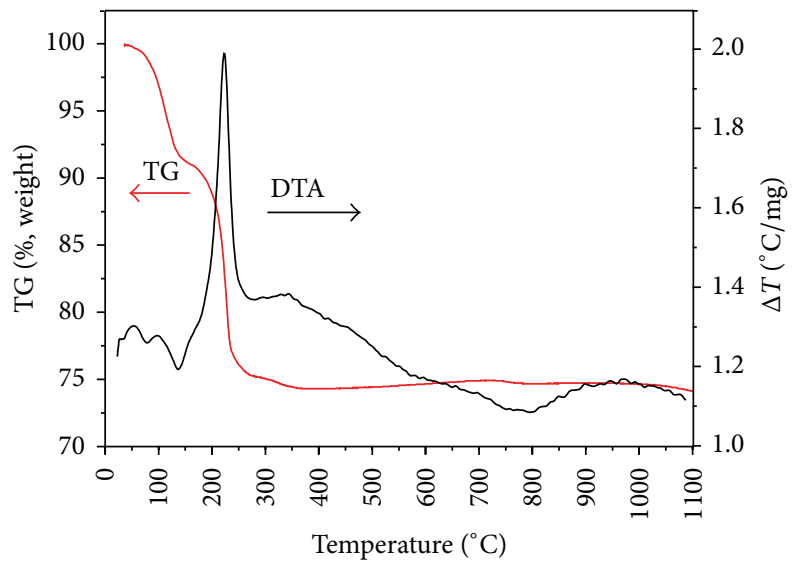

FIGURE 1: TG/DTA curve of copper acetate precursor.

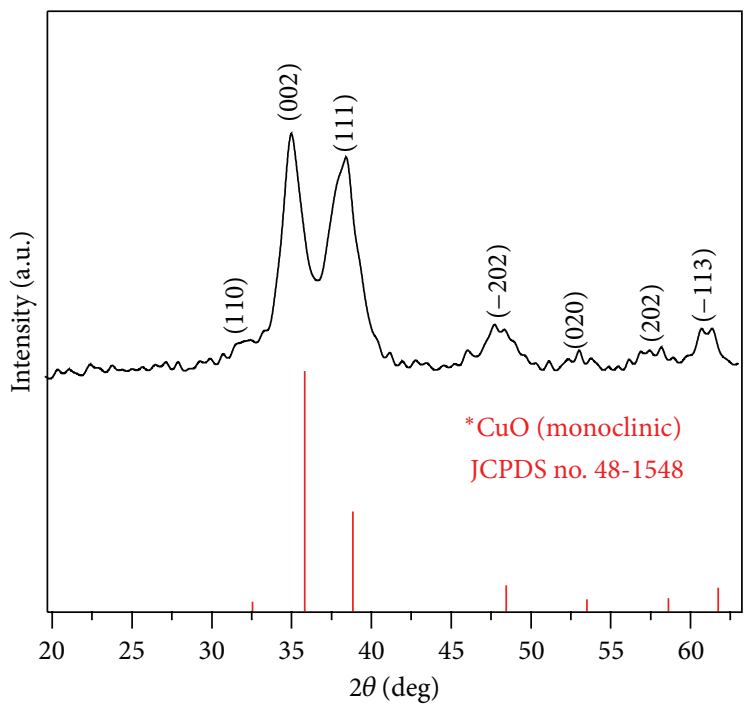

FIGURE 2: XRD patterns of $\mathrm{CuO}$ nanoparticles.

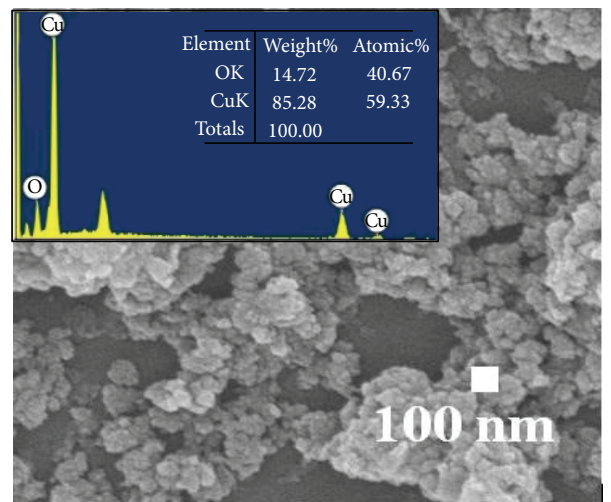

(a)

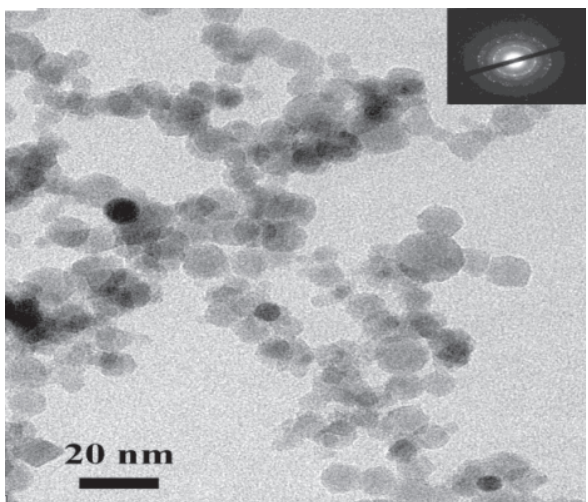

(b)

FIGURE 3: (a) SEM/EDS analyses and (b) HRTEM image of $\mathrm{CuO}$ morphologies. Insets show the corresponding diffraction patterns of the particles related to the $\mathrm{CuO}$ lattice planes. 
morphology and estimated particle sizes, TEM images can reveal internal structure and a more accurate measurement of particle size and morphology. The corresponding EDS spectrum can also confirm the presence of $\mathrm{Cu}$ and $\mathrm{O}$ elements in sample. The spherical $\mathrm{CuO}$ nanoparticles are evaluated by EDS quantitative analysis software (Oxford Instrument) and found to have 59.33 at $\%$ of $\mathrm{Cu}$ and 40.67 at\% of $\mathrm{O}$. If it is in atomic \%, theoretically the $\mathrm{Cu}$ will be $50 \%$ and $\mathrm{O}$ will be $50 \%$. But in the experimental found 59.33 at $\%$ of $\mathrm{Cu}$ and 40.67 at $\%$ of $\mathrm{O}$. Because of the EDS, analysis techniques can select only one area. Thus the amount of $\mathrm{Cu}$ and $\mathrm{O}$ in difference area may be difference values, so in the dispersion of $\mathrm{CuO}$ nanoparticles were found into a high and poor dispersion, respectively as shown in Figure 3(a). The HRTEM brightfield images of $\mathrm{CuO}$ nanoparticles presented in Figure 3(b) revealed spherical morphology of the synthesized nanoparticles with the crystallite size of 5-15 nm. The corresponding diffraction pattern of the nanoparticles was in an inset which clearly indicated the $\mathrm{CuO}$ lattice planes. Thus, the results from $\mathrm{XRD}, \mathrm{BET}$, and HRTEM also confirmed the morphological properties of $\mathrm{CuO}$ nanoparticles by controlling the condition of ethanediol route.

\section{Conclusion}

The ethanediolthermal route was used to synthesize $\mathrm{CuO}$ nanoparticles by controlling the fictionalization of physical properties. The XRD spectrum can be observed to confirm the monoclinic phase of $\mathrm{CuO}$, and the corresponding calculated size was $6.1 \mathrm{~nm}$. The $\mathrm{SSA}_{\mathrm{BET}}$ was found to be $99.67 \mathrm{~m}^{2} / \mathrm{g}$ $\left(d_{\mathrm{BET}}\right.$ of $\left.9.3 \mathrm{~nm}\right)$. The HRTEM revealed spherical morphology of $\mathrm{CuO}$ nanoparticles with the crystallite size ranging from 5 to $15 \mathrm{~nm}$.

\section{Conflict of Interests}

The authors declare that there is no conflict of interests regarding the publication of this article.

\section{Acknowledgments}

The authors would like to gratefully acknowledge the support from the Program in Materials Science, Faculty of Science, Maejo University, and Materials Science Research Center, Faculty of Science, Chiang Mai University, Chiang Mai, Thailand.

\section{References}

[1] C. Noguera, Physics and Chemistry at Oxide Surfaces, Cambridge University Press, Cambridge, UK, 1996.

[2] H. H. Kung, Transition Metal Oxides: Surface Chemistry and Catalysis, Elsevier, Amsterdam, The Netherlands, 1989.

[3] V. E. Henrich and P. A. Cox, The Surface Chemistry of Metal Oxides, Cambridge University Press, Cambridge, UK, 1994.

[4] A. F. Wells, Structural Inorganic Chemistry, Oxford University Press, New York, NY, USA, 6th edition, 1987.
[5] W. A. Harrison, Electronic Structure and the Properties of Solids, Dover, New York, NY, USA, 1989.

[6] M. Fernández-García, A. Martínez-Arias, J. C. Hanson, and J. A. Rodríguez, "Nanostructured oxides in chemistry: characterization and properties," Chemical Reviews, vol. 104, pp. 4063-4104, 2004.

[7] R. W. G. Wyckoff, Crystal Structures, John Wiley and Sons, New York, NY, USA, 2nd edition, 1964.

[8] G. Ertl, H. Knozinger, and J. Weitkamp, Eds., Handbook of Heterogeneous Catalysis, Wiley-VHC, Weinheim, Germany, 1997.

[9] M. Shelef, G. W. Graham, and R. W. McCabe, in Catalysis by Ceria and Related Materials, A. Trovarelli, Ed., chapter 10, Imperial College Press, London, UK, 2002.

[10] D. Stirling, The Sulfur Problem: Cleaning Up Industrial Feedstocks, Royal Society of Chemistry, Cambridge, UK, 2000.

[11] A. Sherman, Chemical Vapor Deposition for Microelectronics: Principles, Technology and Applications, Noyes Publications, Park Ridge, NJ, USA, 1987.

[12] P. Ayyub, V. R. Palkar, S. Chattopadhyay, and M. Multani, "Effect of crystal size reduction on lattice symmetry and cooperative properties," Physical Review B, vol. 51, no. 9, pp. 6135-6138, 1995.

[13] H. Zhang and J. F. Banfield, "Thermodynamic analysis of phase stability of nanocrystalline titania," Journal of Materials Chemistry, vol. 8, no. 9, pp. 2073-2076, 1998.

[14] V. M. Samsonov, N. Y. Sdobnyakov, and A. N. Bazulev, "On thermodynamic stability conditions for nanosized particles," Surface Science, vol. 532-535, pp. 526-530, 2003.

[15] J. B. Forsyth and S. Hull, "The effect of hydrostatic pressure on the ambient temperature structure of CuO," Journal of Physics, vol. 3, no. 28, article 001, pp. 5257-5261, 1991.

[16] A. El-Trass, H. Elshamy, I. El-Mehasseb, and M. El-Kemary, "CuO nanoparticles: synthesis, characterization, optical properties and interaction with amino acids," Applied Surface Science, vol. 258, no. 7, pp. 2997-3001, 2012.

[17] R. Uauy, M. Olivares, and M. Gonzalez, "Essentiality of copper in humans," The American Journal of Clinical Nutrition, vol. 67, no. 5, pp. 952-959, 1998.

[18] C. K. Sen, S. Khanna, M. Venojarvi et al., "Copper-induced vascular endothelial growth factor expression and wound healing," The American Journal of Physiology, vol. 282, no. 5, pp. H1821H1827, 2002.

[19] D. H. Baker, "Cupric oxide should not be used as a copper supplement for either animals or humans," Journal of Nutrition, vol. 129, no. 12, pp. 2278-2279, 1999.

[20] G. Borkow, J. Gabbay, A. Lyakhovitsky, and M. Huszar, "Improvement of facial skin characteristics using copper oxide containing pillowcases: a double-blind, placebo-controlled, parallel, randomized study," International Journal of Cosmetic Science, vol. 31, no. 6, pp. 437-443, 2009.

[21] G. Borkow, C. Z. Richard, and G. Jeffrey, "Improvement of facial skin characteristics using copper oxide containing pillowcases: a double-blind, placebo-controlled, parallel, randomized study," Medical Hypotheses, vol. 73, pp. 883-886, 2009.

[22] G. Borkow and J. Gabbay, "Copper as a biocidal tool," Current Medicinal Chemistry, vol. 12, no. 18, pp. 2163-2175, 2005.

[23] G. Borrow and J. Gabbay, "Putting copper into action: copperimpregnated products with potent biocidal activities," The FASEB Journal, vol. 18, no. 14, pp. 1728-1730, 2004.

[24] J. J. Hostynek and H. I. Maibach, "Copper Hypersensitivity: dermatologic aspects. An overview," Reviews on Environmental Health, vol. 18, no. 3, pp. 153-183, 2003. 
[25] C. Siriwong, N. Tamaekong, and S. Phanichphant, "Characterization of single phase $\mathrm{Pt}$-doped $\mathrm{Zn}_{2} \mathrm{TiO}_{4}$ nanoparticles synthesized by flame spray pyrolysis," Materials Letters, vol. 68, pp. 97-100, 2012.

[26] A. Torres, T. Ruales, C. Pulgarin et al., "Innovative high surface area $\mathrm{CuO}$ pretreated cotton effective in bacterial Inactivation under visible light," in Proceedings of the International Conference on Antimicrobial Research (ICAR '11), A. Mendez-Vilas, Ed., Science and Technology against Microbial Pathogens: Research, Development and Evaluation, pp. 160-163, World Scientific Publishing, 2011.

[27] N. M. Hosny and M. S. Zoromba, "Polymethacrylic acid as a new precursor of $\mathrm{CuO}$ nanoparticles," Journal of Molecular Structure, vol. 1027, pp. 128-132, 2012.

[28] B. Cullity, Elements of X-Ray Diffraction, A.W.R.C. Inc, 1967. 

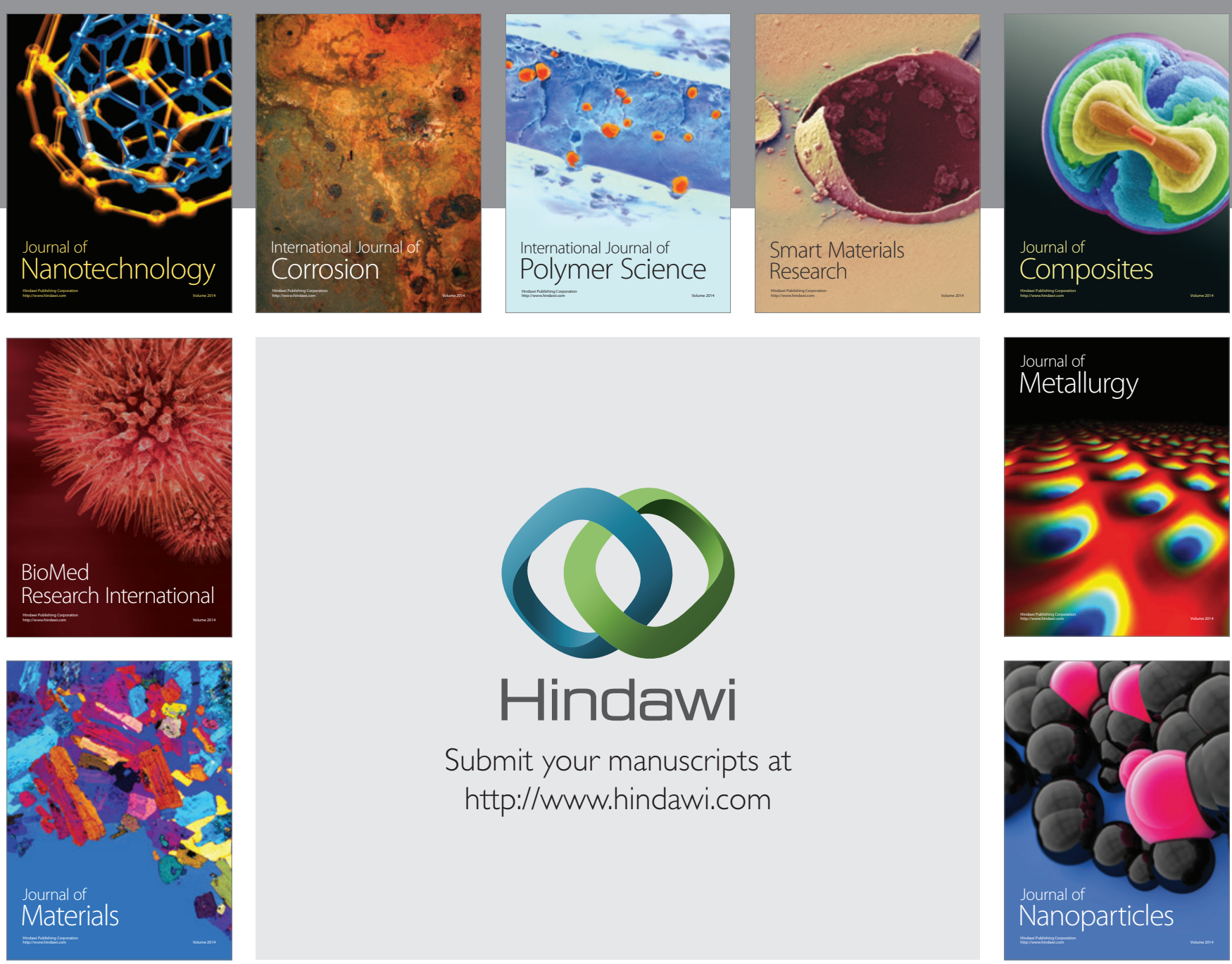

Submit your manuscripts at http://www.hindawi.com
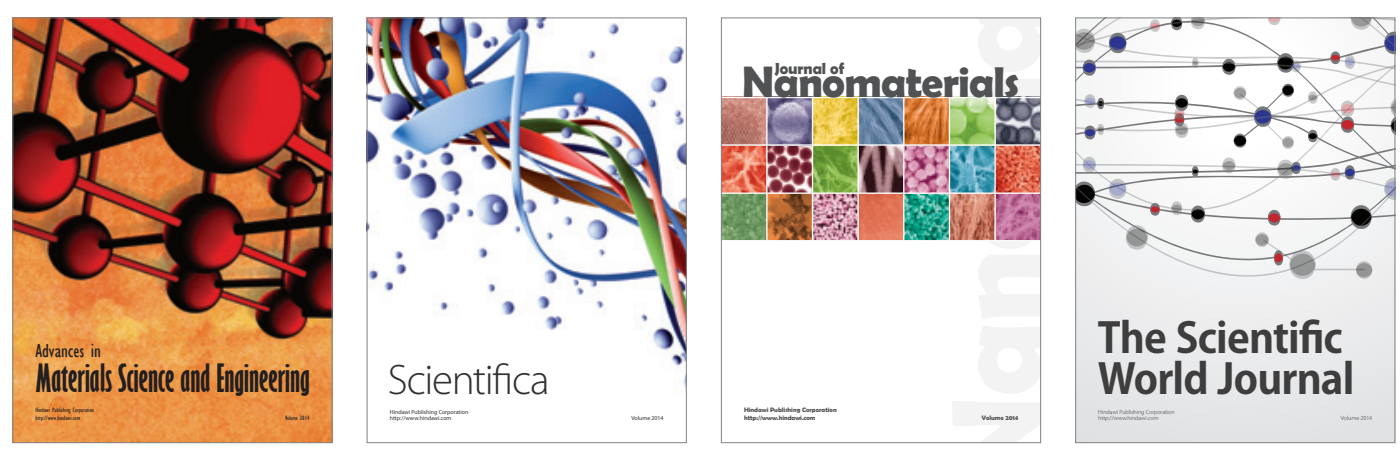

\section{The Scientific World Journal}
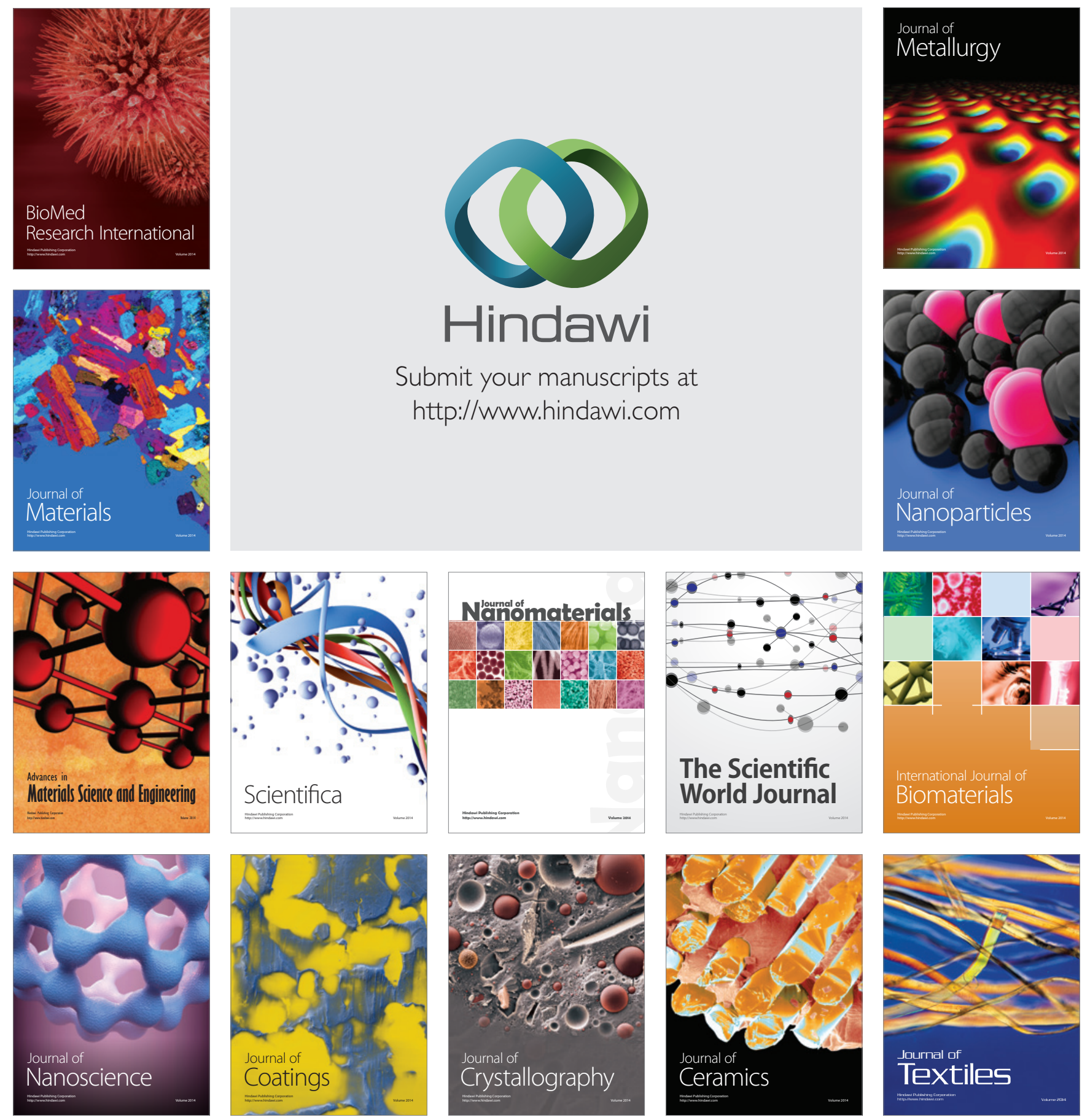